CLINICAL REVIEW

\title{
Cardiac achalasia in childhood
}

\author{
HARJIT SINGH \\ M.D. \\ Senior Lecturer in Paediatrics \\ R. S. SETHI
M.S.
Assistant Professor of Surgery
}

\author{
H. L. GUPTA \\ M.D., D.T.M.
}

Professor of Paediatrics

S. K. KHETARPAL
M.D., D.C.H.
Assistant Professor of Paediatrics

Rohtak-Haryana Medical College and Hospital, India

\section{Summary}

Cardiac achalasia is a disorder not unknown in the paediatric age-group and may occur even in the neonatal period. This disorder should, therefore, be considered in all cases presenting with persistent vomiting, as well as in those with chronic respiratory disease in whom more common causes have been excluded.

It is almost universally accepted that the disorder results from a disturbed function of ganglion cells in the distal oesophagus, as the disease has been reproduced in laboratory animals by denervation of the distal oesophagus. The exact pathogenesis of this degenerative change is not well understood. However, in at least some of the cases congenital absence of the ganglion cells may be responsible for this functional disturbance. This is inferred from the fact that the disease may be found in association with Hirschsprung disease, in which there is a congenital absence of ganglion cells in the terminal colon. Moreover, the occurrence of the disease in the neonatal period itself favours a congenital lesion.

Surgery was preferred to other forms of treatment in the paediatric age-group in view of the reported equivocal response to mechanical dilatation and predisposition of children to respiratory complications. The results of surgery were satisfactory.

\section{Introduction}

Cardiac achalasia (cardiospasm, mega-oesophagus, oesophageal dystonia) is a non-organic stenosis of the lowermost portion of the oesophagus. The obstruction is localized to a few centimetres at the caudal end of the oesophagus. Though the credit for the first description of the disease goes to Thomas Wallis (Steichen, Heller \& Ravitch, 1960) the word 'cadiospasm' was first used by von Mickulicz in the year 1882. Paul \& Pallewalla (1961) preferred the term 'cardiac achalasia' to 'cardiospasm', since the latter implied spasm as a major cause of obstruction. The disorder is a functional obstruction of the cardia and results from a failure of relaxation of the sphincter.

Although one of the commonest disorders of the oesophagus in adults, cardiac achalasia is rarely considered a paediatric problem, as it seldom manifests in childhood. Abt (quoted by Birnberg, 1929) commented on the rarity of the disease in infancy and childhood. Out of 690 consecutive cases of the disease seen at the Mayo Clinic, only twelve $(1 \cdot 72 \%)$ presented in the paediatric age-group (Moersch, 1929). In the series of 601 cases reported by Olsen, Holman \& Andersen (1953), there were only seventeen children; only twenty-seven children attended the Mayo Clinic over a 24-year period.

Presenting features in children may be atypical and at times be overshadowed by the respiratory symptoms secondary to the disease (Schultz, 1961). However, early diagnosis is imperative particularly in view of the respiratory complications in longstanding cases (Swenson \& Oeconomopoulos, 1961). Since even standard textbooks of paediatrics fail to give more than a passing reference to cardiac achalasia, this review is intended as a reminder to those involved in the care of children. 


\section{Pathogenesis}

Hoffman (quoted by Thieding, 1921) stressed the role of personality in the disease; he ascribed the condition to 'irrational tone' and 'uncontrolled desires'. Frinkelstein (quoted by Segar \& Stoeffler, 1929) while reporting two cases of 'oesophagism on a spasmophilic basis', in two rachitic children, incriminated vitamin $\mathbf{D}$ deficiency as the cause. The disease had been associated with trauma to the chest by earlier workers (Purton, 1821; Hannay, 1833; von Rokitansky, 1842). One group maintained that it was a mechanical obstruction-whether fibrotic, diaphragmatic pinch-cock or any other lumenobliterating factor (Jackson, 1922; Mosher, 1935). Perhaps a more rational approach was that of Meltzer (1888), revived by Einhorn (quoted by Kramer \& Ingelfinger, 1949), Rolleston (1896), Hurst (1915) and Alvarez (1940). These workers considered it to be a 'neuromuscular dysfunction' that prevented receptive relaxation of the cardia before an advancing peristaltic wave. The cause of this dysfunction has been sought in congenital abnormality (Fleiner, 1900), nutritional deficiency (Merril \& Richards, 1941; Etzel, 1942) and emotional state (Weiss, 1944; Moschcowitz, 1947).

Evidence has been accumulating in support of the view first expressed by Hurst \& Rake (1930) that the condition results from degeneration, necrosis and fibrotic replacement of nerve ganglion cells of the myenteric plexus at the lower end of the oesophagus (Lendrum, 1937; Cross, 1952; Trounce, 1957). Changes are most marked in the distal segment of oesophagus including the constricted portion. Sections taken immediately below the undilated portion show normal ganglion cells. The condition has been reproduced in laboratory animals by denervation of the distal oesophagus (Swenson et al., 1940; Deloyers, Cordier \& Duprez, 1957; Alnor, 1958). Intraluminal response to drugs, in this disease, is characteristic of the denervated intestine (Kramer \& Ingelfinger, 1951; Sliesinger, Steinberg \& Almy, 1953).

Cardiac achalasia has been compared, functionally and pathologically, with Hirschsprung disease as both the diseases show an absence of the ganglion cells in their walls. While the defect is a congenital one in megacolon, studies in achalasia suggest an inflammatory or degenerative process. However, congenital absence of ganglion cells, in at least some of the cases, cannot be ruled out as the disease at times manifests in the neonatal period. A combination of cardiac achalasia and Hirschsprung disease has been reported (Swenson \& Oeconomopoulos, 1961).

\section{Oesophageal motility in achalasia}

Physiologists describe three types of oesophageal contraction: (1) the primary peristaltic wave,
(2) secondary peristaltic wave, and (3) localized contractions tonic and segmental in nature. The primary wave is initiated by the act of deglutition and is the major propelling force of the bolus; this is preceded by a wave of inhibition which relaxes the musculature ahead of the bolus. The secondary contractions start at the level of the aortic arch and are initiated by distension of the oesophagus; these are observed in patients in whom the primary contraction fails to carry the bolus. The third type of contractions may not be entirely normal and are not usually observed in young people. These movements occur in the lower part of the oesophagus and during contraction the lumen assumes a peculiar, irregular, serrated appearance. The significance of these 'tertiary' contractions is not well understood.

Oesophageal motility in cardiac achalasia has been studied by several workers (Templeton, 1948; Kramer \& Ingelfinger, 1949; Butin, Olsen \& Moersch, 1953). These workers found the oesophageal muscular activity in this condition to be at variance with the normal pattern. In this disease the primary wave ends at about the level of the suprasternal notch and secondary waves are not observed. In most cases purposeless, shallow, segmental contractions constantly appear and disappear but are not of sufficient force to move the bolus. These movements simulate the tertiary contractions in an exaggerated form. Another type of contraction observed by Templeton (1948) resembled generalized tonic contractions which diffusely narrowed the oesophageal lumen and forced the contents down into the stomach.

\section{Clinical features}

Obstruction during swallowing and regurgitation of feeds are the most frequent presenting complaints (Payne, Ellis \& Olsen, 1960a). Moersch (1929) in a study of thirty-four children, found dysphagia to be the first symptom in the majority of the cases. Children either regurgitate solid food or wash it down with gulps of water. Some children develop habits like breathing deeply and crouching forwards while eating, to overcome the difficulty (Moersch, 1933; Vinson, 1948). Most workers have reported as much disability with fluids as with solids, but Womack, Britnell \& Ehrenhart (1951) found the difficulty to be much more with solids as compared with fluids. As a result of the disability the children are unable to take a complete meal and may demand snacks between meals due to hunger.

The earliest evidence of regurgitation is generally in the form of food remnants on a child's pillow. Nocturnal regurgitation was present in five out of six cases reported by Swenson \& Oeconomopoulos (1961). In a series of 108 adult cases, Payne et al. (1960a) reported regurgitation in $89 \%$ of the cases. The regurgitated food is unmixed with gastric juice. 
Weight-loss is the inevitable result of disturbed nutrition and is seen in the majority of the cases. Retrosternal pain which is an important symptom of adult cases, is not commonly complained of by children. In their study of twenty-seven children, Payne et al. (1960a) obtained a history of retrosternal pain in less than half the cases.

Occasionally the primary illness may be masked by respiratory symptoms. Due to spill-over of regurgitated food, there are attacks of coughing and choking at night. Swenson \& Oeconomopoulos (1961) reported nocturnal cough in three of their six cases. The importance of respiratory symptoms as a result of nocturnal regurgitation has been emphasized (Plummer \& Vinson, 1921). Sudden death by aspiration of oesophageal contents has been reported (Breakey, Dotter \& Steinberg, 1951) and these workers collected forty-seven cases with respiratory complications. These complications, which are observed in about $10 \%$ of the adult cases (Vinson, 1924; Lake, 1951; Andersen, Holman \& Olsen, 1953), are much more common in children and were observed in $33 \%$ of the cases reported by Payne et al. (1960b). Respiratory complications include recurrent respiratory infections, bronchiectasis, lung abscess, pneumonitis, bronchitis, bronchial obstruction, atelectasis and empyema (Vinson, 1927; Moersch, 1933; Schrire, 1938; Belcher, 1949; Helm, 1952; Davies and Roberts, 1955). Chronic cough is the most common presenting complaint.

The presence of non-pathogenic acid-fast bacilli in the sputum (Gibson, 1953) coupled with radiological evidence of chronic infiltration and fibrosis, makes the differentiation from tuberculosis difficult at times.

\section{Diagnosis}

The disease has to be differentiated from organic obstruction of the cardia due to neoplasm or fibrotic stricture and from diffuse spasm of the oesophagus. A benign neoplasm located at or near the cardia may cause chronic obstruction resulting in prolonged stasis of food and fluid with secondary dilatation of the oesophagus. Intraluminal growths may at times be indistinguishable, radiologically, from accumulated food due to achalasia. Similarly differentiation from carcinoma of the cardia may be difficult or impossible in the earlier stages. However, these conditions are rare in the paediatric age-group.

In diffuse spasm of the oesophagus, the obstruction begins at the mid-oesophagus and extends all the way down to the stomach. This condition may be difficult to differentiate clinically or radiologically (Olsen et al., 1951). Endoscopy plays a limited role in the diagnosis, but no useful purpose is served by passing an endoscope into an organ filled with food and debris. Radiology is the only useful diagnostic aid.

\section{Radiological appearances}

The earliest change is obstruction of the cardia with slight dilatation of the oesophagus. As the disease advances the oesophagus dilates and becomes elongated. In an advanced stage of the disease the hugely dilated oesophagus can be visualized on a straight postero-anterior projection of the chest (Fig. 1). Four stages of the disease have been described radiologically (O!sen et al., 1951). In Stages 1 and 2, the compensated phase of the disease, there is a thickening of the musculature and increased though ineffectual muscular activity. In Stages 3 and 4, the phase of decompensation, the oesophagus is virtually silent and there is a progressive dilatation and angulation. The detailed radiological changes are:

Stage 1: There is a slight dilatation, the oesophagogastric junction appears narrowed and some fluid is retained in the lower $5-10 \mathrm{~cm}$ of the lumen (Fig. 2). Following ingestion there may be some increase in muscular activity, which is principally in the form of a short succession of secondary waves.

Stage 2: The oesophagus is moderately dilated and classical signs of the disease develop. The lumen at the lower end is conical and narrowed to a beak-like extension into the narrowed segment (Fig. 3). Some increase in muscular activity may be noticed. Small amounts of barium do pass into the stomach in spite of marked narrowing.

Stage 3: There is diffuse dilatation and a long column of food and fluid is present in the lumen through which the barium drifts downwards (Fig. 4). The dilated segment abruptly terminates in a short tapered segment, smooth in outline, which ends in a short pointed beak. Occasionally a small amount of barium passes into the stomach. There is no bubble of gas in the stomach.

Stage 4: There is marked dilatation, angulation and elongation of the oesophagus. Occasionally it is grossly dilated and occupies the entire right half of the thoracic cavity. Frequently the lower onethird assumes an S-shape and is referred to as the sigmoid oesophagus (Fig. 5). A narrowed segment can usually be identified and barium does pass into the stomach.

Following treatment, changes in muscular activity of the oesophagus are frequently demonstrable. Contractions are evident after therapy unless the condition had been too far advanced. Ordinarily the food and fluid are not retained in the oesophagus (Fig. 6).

\section{Treatment}

Anti-cholinergics have little value in the treatment of cardiac achalasia; aggravation of symptoms 


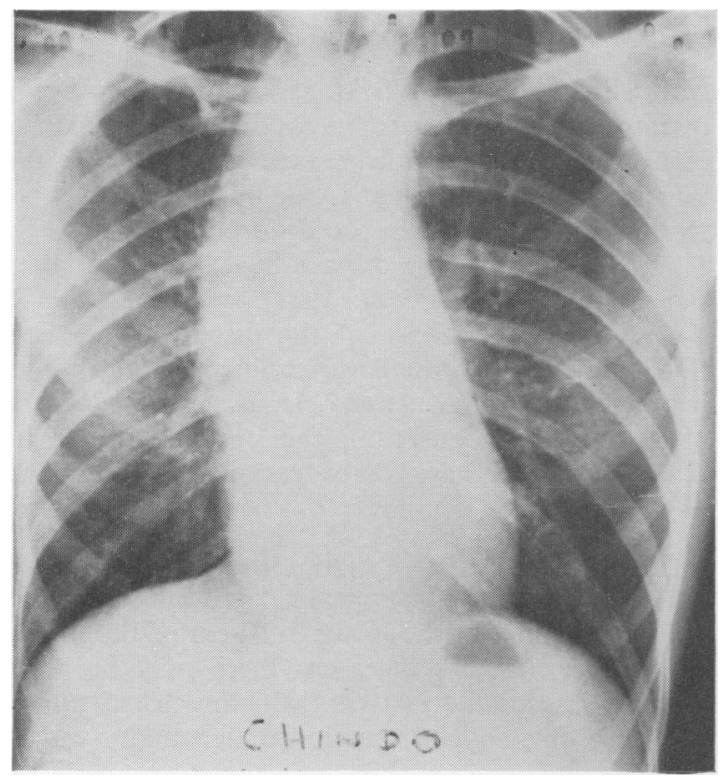

Fig. 1. Postero-anterior projection of chest showing widened mediastinum due to oesophageal dilatation.

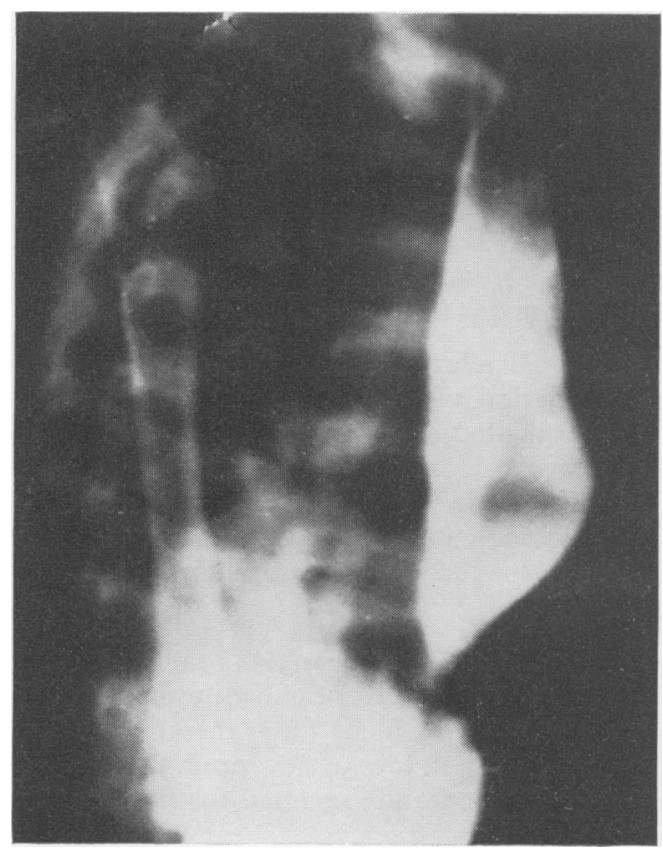

FIG. 2. Dionosil study in a 2-month-old infant showing a slightly dilated oesophagus ending in a narrow segment at the oesophago-gastric junction. The meal has, however, passed into the stomach.

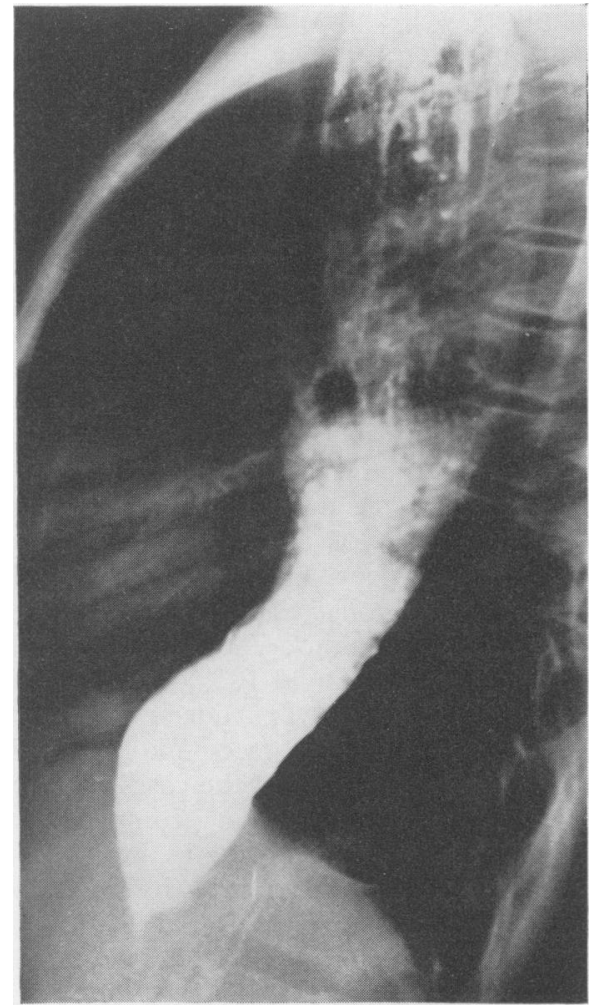

FIG. 3. Barium study showing a classical 'beak-like' narrowing at the oesophago-gastric junction.

following their use has been reported (Texter et al., 1956). The only two established methods of treatment have been mechanical dilatation and surgery.

The first pneumatic dilator was described by Russel (1898). Plummer's hydrostatic dilator (Plummer, 1906), which has been extensively used for mechanical dilatation, was a modification of Russel's dilator. Reports of the usefulness of this technique in adults (Plummer \& Vinson, 1921; Freeman, 1940; Vinson, 1948; Nagel, 1949) and in children (Moersch, 1929) have been accumulating. Ria \& Campos (quoted by Swenson \& Oeconomopoulos, 1961) considered mechanical dilatation as the most benign, easiest and least costly procedure. However, Fritz, Clark \& Adams (1951) and Sifers \& Criles (1960) considered this method to be not so satisfactory. Olsen et al. (1951) while recording the results of mechanical dilatation in 452 cases of achalasia treated at the Mayo Clinic, reported good results in $80 \%$ of the cases thus treated ; the remainder failed to obtain permanent relief. These workers observed that if permanent relief was not obtained with the first or second treatments, further dilatations were unlikely to produce favourable results. They encountered haemorrhage, aspiration pneumonia 


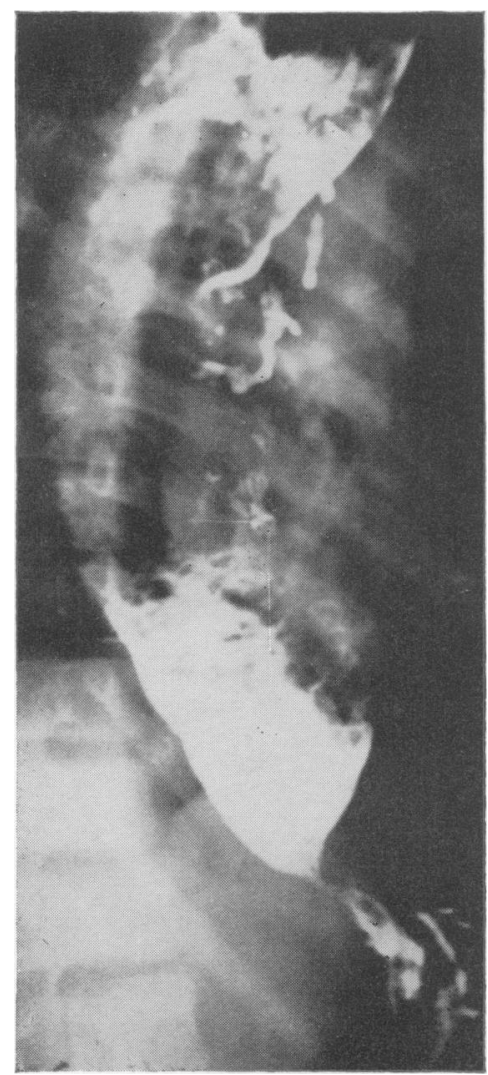

FIG. 4. Barium study showing a markedly dilated oesophagus; the meal percolates through a column of food debris.

and rupture of oesophagus as complications. There was only one death in this series and that resulted from oesophageal rupture and subsequent mediastinitis. In view of the reported good results with mechanical dilatation, Swenson \& Oeconomopoulos (1961) used this method to treat six children; prompt relief occurred in all the six but the symptoms recurred in two who ultimately required surgery.

Several surgical procedures have been used to relieve the obstruction (Wendel, 1910; Heller, 1913; Wangensteen, 1951, 1957; Merendino \& Dillard, 1955; Merendino, 1956; Tuttle, Crowley \& Barett, 1958). However, the surgical procedure initiated by Heller (1913) and subsequently modified by Zaaiger (1923) has been the one most commonly employed. Heller's operation consists of a myotomy along the anterior wall of the oesophagus, exposing the mucosa and extending 1-2 $\mathrm{cm}$ above and below the stenotic portion. Although Richman (1956), Root (1958) and Farrar (1959) recorded poor results and Hawthorne, Frobese \& Nemir (1956) and Acheson \& Hadley (1958) found the late results to be not entirely satisfactory, most reports confirm the good

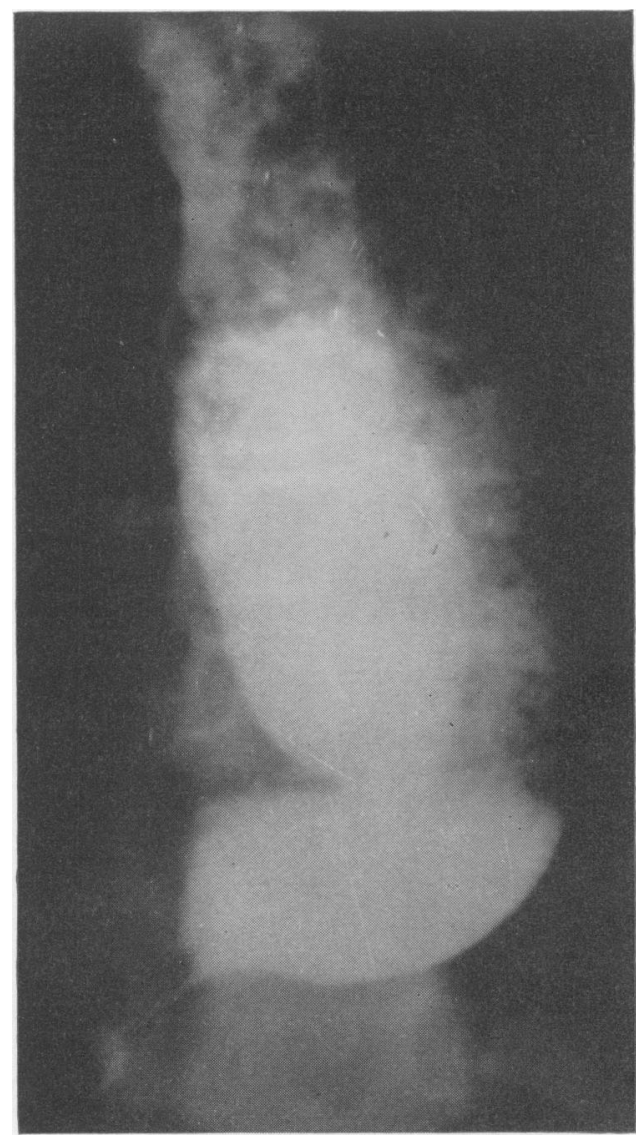

Fig. 5. The 'sigmoid' oesophagus.

results (Effler \& Rogers, 1955; Sweet, 1956; Ellis et al., 1958; Gammie, Jennings \& Richardson, 1958; Abbot, McKenzie \& Ross, 1959; Hasche \& Schubert, 1959; Laurence \& Shoesmith, 1959). Gammelgaard, Iverson \& Thomson (1956) reported good results in $84 \%$ of the cases thus treated. Swenson \& Oeconomopoulos (1961) considered it to be the best operation for mild and moderate cases and recommended Wendel's operation for the advanced cases. Womack et al. (1951) also recommended surgical treatment for cases in the paediatric age-group.

\section{Case reports \\ Case No. 1}

A 10-year-old female child was admitted complaining of vomiting, difficulty in swallowing and nocturnal regurgitation. The symptoms began at 4 years of age with the vomiting of food taken during the previous feeds. This continued for 2 years when the patient developed the sensation of food sticking behind the sternum. Relief could be obtained by taking a few gulps of water or by induced vomiting. 


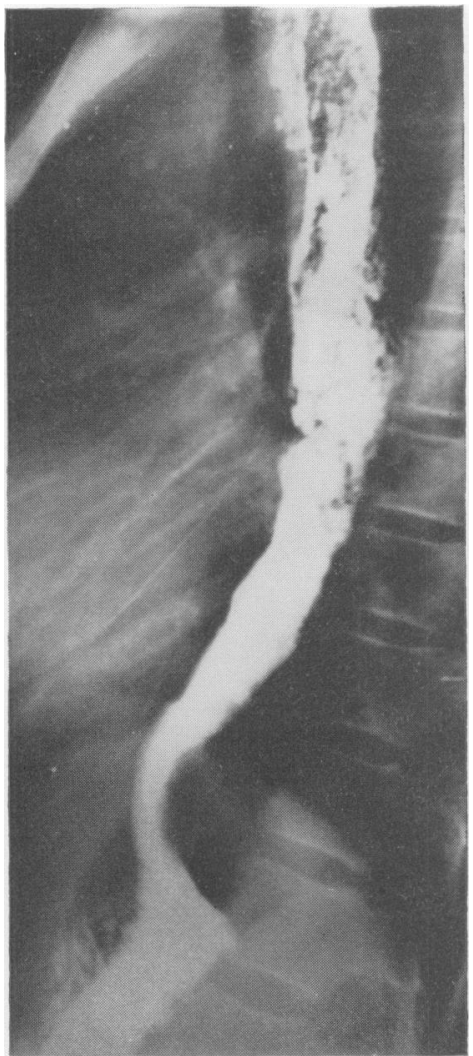

FIG. 6. Post-operative barium study in Case 3 showing no narrowing at the oesophago-gastric junction.

Two years prior to admission the patient started having nocturnal regurgitation of food and recurrent attacks of respiratory infection. By the time of admission she had learned to overcome the disability by forcing down solid food with gulps of water and by crouching forwards after taking food.

On examination she was poorly built and anaemic, and weighed only $16 \mathrm{~kg}$. There was a microcytic hypochromic anaemia, $\mathrm{Hb} 11.2 \mathrm{~g} / 100 \mathrm{ml}$. A skiagram of the chest (Fig. 7) showed widening of the mediastinum with increased bronco-vascular markings. Barium meal showed a markedly dilated oesophagus with barium drifting through a column of food and collecting at the lower end of the oesophagus into a tapered segment (Fig. 4). Heller's oesophagomyotomy relieved the patient's symptoms. A barium study 2 weeks later still showed a moderately dilated oesophagus that contained no food debris and there was no obstruction at the lower end (Fig. 8). The patient was asymptomatic a year after the operation.

\section{Case No. 2}

M.S., a 12-year-old male child was admitted with

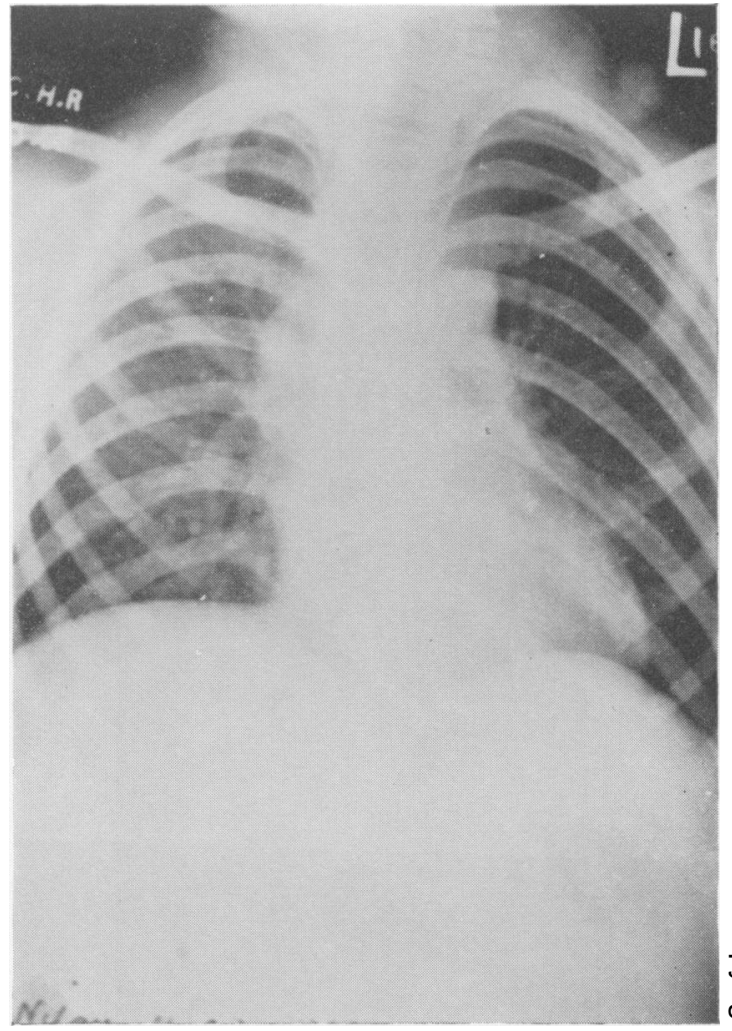

FIG. 7. Skiagram of the chest in Case 1 showing a widening of the mediastinum with increased bronchovascular markings.

a history of vomiting for 6 months prior to admission. Vomiting had occurred at varying intervals after taking food and the vomitus contained food taken in the previous meal as well as that taken up to $36 \mathrm{hr}$ earlier. While taking food the patient had a sensation of food sticking behind the sternum. The disability was as great with fluids as with solids. He had gradually lost weight.

On examination he was undernourished and anaemic; PA film of the chest showed a widening of the mediastinum with a soft tissue shadow on the right side extending $1 \mathrm{~cm}$ beyond the cardiac shadow. A barium meal showed a markedly dilated oesophagus, angulated in the lower part, with the lumen terminating abruptly in a narrow segment. The patient was relieved of symptoms by a Heller's cardiomyotomy.

\section{Case No. 3}

C., an 11-year-old girl, was admitted with complaints of vomiting and nocturnal regurgitation of fluids through the nose for 6 months prior to admission. The illness had begun with difficulty in swallowing solids which later became associated 


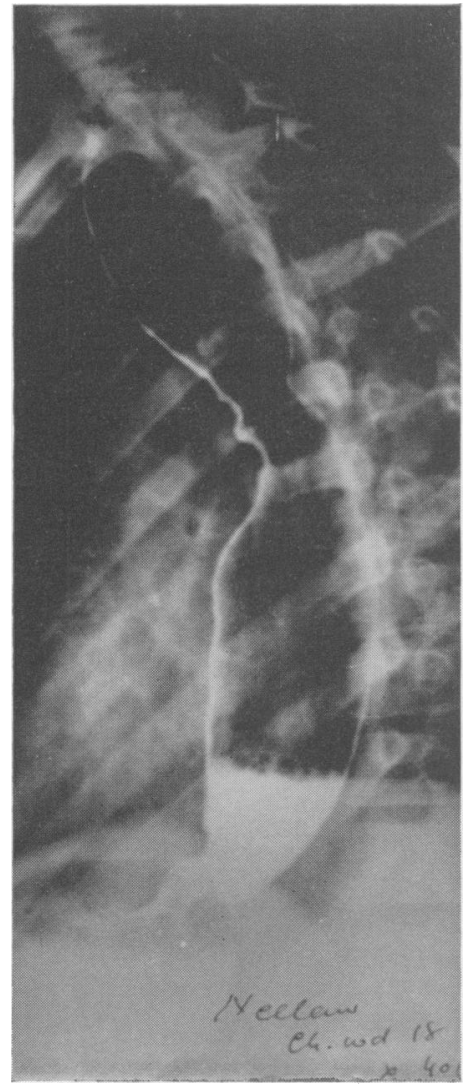

FIG. 8. Post-operative barium study in Case 1 showing no obstruction at the lower end of the oesophagus.

with vomiting food taken in previous meals. The pillow had repeatedly been soiled by regurgitated food and she had bouts of nocturnal coughing.

On examination she was poorly built and emaciated and had an iron-deficiency type of anaemia. A plain skiagram of the chest (Fig. 1) showed a widening of the mediastinum due to a dilated oesophagus and bronchiectatic changes in the lungs. Barium meal showed radio-opaque material drifting through food debris in the oesophagus and settling down at the lower end into a tapered segment. A Heller's cardiomyotomy relieved her symptoms. A repeat barium meal 4 weeks later showed a normal-sized oesophagus with no narrowing at the lower end.

\section{Achalasia in infancy}

Though cases of cardiac achalasia are on record in the newborn period (Birnberg, 1929; Segar \& Stoeffler, 1930; Van der Bogart, 1933; Haas, 1941; Thomson, 1950) and in infancy (Hess, 1914; Bruce, 1927; Messeloff, Shulman \& Buckstein, 1928), it was doubted whether this disease existed in infancy at all, particularly in view of marked symptomatic improvement with simple procedures like gastric intubation and administration of atropine. However, the report of a 6-month-old infant by Paul \& Pallawela (1961), who had radiologic evidence of achalasia and who subsequently showed thickened muscle coats in the distal oesophagus, puts all such doubts aside. Morgan (1911) reported a case who started vomiting at 3 weeks of age. A catheter was passed with some difficulty through the cardia resulting in relief of symptoms. Longmead (1920) cited the case of an infant who vomited from the first feed. Barium study of the oesophagus showed a collection of radio-opaque material in the lower dilated portion. However an oesophagoscope passed freely into the stomach, revealing no organic obstruction.

Recent literature on achalasia makes little mention of the disease in infancy. A patient who was admitted under our care is reported below.

\section{Case No. 4}

A 2-month-old male baby was admitted with a story of vomiting and constipation for $1 \frac{1}{2}$ months. After the first 3 uneventful weeks of extrauterine life, following a full-term normal delivery, the patient began to regurgitate breast-milk feeds through mouth and nose. Vomiting became forceful with the passage of time. The milk vomited was unaltered and unmixed with gastric juice. Vomiting followed every feed and the child accepted another feed readily soon afterwards. He was constipated and had been losing weight. He never developed fever or respiratory distress and was not cyanosed.

On examination he was markedly under-nourished and was slightly dehydrated. The abdominal wall was thin and normal peristaltic waves could be seen. A Dionosil study of the upper gastro-intestinal tract revealed cardiac achalasia.

In view of the good results reported with antispasmodics the patient was treated with Spasmindon (atropine methylnitrate) with prompt relief of symptoms. The patient, however, died of aspiration while still in the hospital.

\section{Acknowledgments}

We wish to thank Dr Indarjit Dewan, Principal, for his kind permission to use hospital data. Thanks are also due to Mr M. L. Sharma for technical help.

\section{References}

Aвbott, C.E., MacKenzie, W.C. \& Ross, C.A. (1959) Surgical treatment of achalasia of the oesophagus. Can. J. Surg. 2, 345.

Acheson, E.D. \& Hadley, G.D. (1958) Cardiomyotomy for achalasia of the cardia: the experience of the Middlesex and Harefield Hospitals up to 1955. Brit. med. J. 1, 549.

AlNoR, P. (1958) On the pathogenesis of cardispasm. $J$. Thoracic Surg. 36, 141.

Alvarez, W.C. (1940) An Introduction to Gastroentrology, pp. 197 and 283. Hoeber, New York. 
Andersen, H.A., Holman, C.B. \& Olsen, A.M. (1953) Pulmonary complications of cardiospasm. J. Amer. med. Ass. 151, 608.

BELCHER, J.R. (1949) The pulmonary complications of dysphagia. Thorax, 4, 44.

BIRNBERG, T.L. (1929) Cardiospasm in the newborn infant. Amer. J. Dis. Child. 38, 1183.

Breakey, A.S., Dotter, C.T. \& Steinberg, I. (1951) Pulmonary complications of cardiospasm. New Engl. J. Med. 245, 441 .

BRUCE, J.W. (1927) Cardiospasm in a 3-years old child. Kentucky med. J. 26, 154.

Butin, J.W., Olsen, A.M. \& MoersCh, H.J. (1953) A study of osesophageal pressures in normal persons and patients with cardiospasm. Gastroentrology, 23, 278.

Cross, F.S. (1952) Pathologic changes in megaoesophagus. Surgery, 31, 647.

Davies, D. \& RoberTs, J.C. (1955) Achalasia of the cardia in adolescents presenting with respiratory symptoms. Lancet, i, 840 .

Deloyers, L., Cordier, R. \& Duprez, A. (1957) A new approach to the physiology of so-called 'cardiospasm'. Ann. Surg. 146, 167.

EFfleR, D.B. \& Rogers, J.W. (1955) Megaoesophagus: surgical therapy. Arch. Surg. 71, 551.

Ellis, F.H., JR, Olsen, A.M., Holman, C.B. \& Code, C.F. (1958) Surgical treatment of cardiospasm (achalasia of the oesophagus): considerations of aspects of esophagomyotomy. J. Amer. med. Ass. 166, 29.

Etzel, E. (1942) May a disease complex that includes megaoesophagus (cardiospasm), megacolon and megauretor be caused by chronic vitamin $\mathrm{B}_{1}$ deficiency? Amer. J. med. Sci. 203, 87.

FARRAR, T. (1959) The surgical treatment of cardiospasm: combined Mikulicz-Heller procedure. Sth med. J. 52, 609.

FleiNer, W. (1900) Neue Beitrage zur Pathologie der Speiserohre. Munchen med. Wschr. 30, 17.

Freeman, E.B. (1940) Symptoms, diagnosis and treatment of chronic cardiospasm. Rev. Gastroentrol. 7, 385.

Fritz, J.M., Clark, D.E. \& Adams, W.E. (1951) The diagnosis and treatment of cardiospasm. Surg. Clin. $N$. Amer. 31, 173.

GammelgaARD, A., Iverson, J. \& Thomson, G. (1956) Cardiospasm, the results of Heller's operation. Acta chir. scand. 111, 98.

Gammie, W.F.P., Jennings, D. \& Richardson, J.E. (1958) Cardiomyotomy (Heller's Operation) for oesophageal achalasia. Lancet, ii, 917.

GiBson, J.B. (1953) Infection of the lung by 'saprophytic' mycobacteria in achalasia of the cardia with report of a fatal case showing lipoid pneumonia due to milk. J. Path. Bact. 65, 239.

HANNAY, A.F. (1833) An extraordinary dilatation of all the portion of the oesophagus causing dysphagia. Edinb. med. J. 40, 65 .

Hasche, E. \& Schubert, H. (1959) Zur Operativum Behandlung der Cardiospasmus. Thorax Chir. 6, 434.

HAAs, V.S. (1941) Relief of cardiospasm in the newborn by administration of atropine sulphate. Amer. J. Dis. Child. 62, 1118

Hawthorne, H.R., Frobese, A.S. \& Nemir, P., JR (1956) The surgical management of achalasia of the oesophagus. Ann. Surg. 144, 653.

Heller, E. (1913) Extramucose Cardioplastic beim Chronichen Cardiospasmus mit Dilatation der Oesophagus. Mitt. Grenzgeb. Med. 27, 141.

Helm, W.H. (1952) Dysphagia pneumonitis. Postgrad. med. J. 28, 247.

Hess, A. (1914) The pylorus, pylorospasm and allied spasms in infants. Amer. J. Dis. Child. 7, 184.
Hurst, A.F. (1915) Achalasia of the cardia. Quart. J. Med. $8,300$.

Hurst, A.F. \& RAKe, G.W. (1930) Achalasia of the cardia. Quart. J. Med. 23, 491.

JACKSON, C. (1922) The diaphragmatic pinch-cock in socalled 'cardiospasm'. Laryngoscope, 32, 139.

Kramer, P. \& INGelfinger, F.J. (1949) II. Cardiospasm, a generalised disorder of oesophageal motility. Amer. J. Med. 7, 174.

Kramer, P. \& Ingelfinger, F.J. (1951) Oesophageal sensitivity of mechlyl in cardiospasm. Gastroentrology, 19, 242.

LAKE, R.A. (1951) Pulmonary changes related to cardiospasm. Ann. intern. Med. 35, 593.

Laurance, K. \& Shoesmith, J.H. (1959) A review of the treatment of cardiospasm. Thorax, 14, 211.

LENDRUM, F.C. (1937) Anatomic features of the cardiac orifice of the stomach. Arch. intern. Med. 59, 474.

Longmead, F. (1920) Oesophagectesis in an infant. Proc. Roy. Soc. Med. 13, 43.

Meltzer, S.G. (1888) Ein Fall von Dysphagia nebst Bemerkungen. Berlin klin. Wschr. 25, 140.

Merendino, K.A. (1956) Important side issues in the treatment of cardiospasm. Editorial. Arch. Surg. 73, 1047.

Merendino, K.A. \& Dillard, D.H. (1955) Concept of sphincter substitution by interposed jujenal segment for anatomic and physiologic abnormalities at oesophagogastric junction with special reference to oesophageal varices. Ann. Surg. 142, 486.

MERRILl, O. \& RichARDS, R. (1941) Dysphagia and nutritional deficiency. New Engl. J. Med. 225, 326.

Messeloff, C. R., Shulman, H. I. \& Buckstein, J. (1928) Cardiospasm in infancy and in childhood. Amer. J. Dis. Childh. 35, 427.

MoersCH, H.J. (1929) Cardiospasm in infancy and childhood. Amer. J. Dis. Child. 38, 294.

MoERSCH, H.J. (1933) Cardiospasm: its diagnosis and treatment. Ann. Surg. 98, 232.

Morgan, W.G. (1911) Cardiospasm in infants. Med. Rec. 80, 173.

Moschcowitz, E. (1947) Essays on the biology of disease. J. Mt Sinai Hosp. 13, 337.

Mosher, H.P. (1935) The oesophagus. Surg. Gynec. Obstet. 60, 403.

Nagel, G. (1949) Cardiospasm. California Med. 71, 285.

Olsen, A.M., Harrington, S.W., Moersch, H.J. \& ANDERSEN, H.A. (1951) The treatment of cardiospasm: analysis of a twelve year experience. J. Thoracic Surg. 22, 164.

Olsen, A.M., Holman, C.B. \& Andersen, H.A. (1953) The diagnosis of cardiospasm. Dis. Chest, 23, 477.

Paul, A.T.S. \& Pallawela, G.D.S. (1961) Unusual forms of achalasia cardia and associated neuro-muscular disorders of the oesophagus. Postgrad. med. J. 37, 514.

Payne, S.W., Ellis, F.H., JR \& Olsen, A.M. (1960a) Treatment of cardiospasm (achalasia of oesophagus) in children. Surgery, 50, 731

Payne, S.W., Ellis, F.H., JR \& Olsen, A.M. (1960b) Achalasia of the oesophagus-a follow-up study of patients undergoing oesophagomyotomy. Arch. Surg. 81, 411.

Plummer, H.S. (1906) Cardiospasm with report of cases. J. Minnesota State med. Ass. Northwestern Lancet, 26, 419.

Plummer, H.S. \& Vinson, P.P. (1921) Cardiospasm: a report of 301 cases. Med. Clin. N. Amer. 5, 355.

Purton, T. (1821) An extraordinary case of distension of oesophagus forming a sac, extending from 2 inches below the pharynx to the cardiac orifice of the stomach. Med. Physiol. J. (Lond.), 46, 540.

Richman, A. (1956) Symposium on diseases of oesophagus. J. Mt Sinai Hosp. 23, 34.

Rolleston, H.P. (1896) Simple dilatation of the oesophagus. Trans. Path. Soc. Lond. 47, 37. 
Root, H.D. (1958) Evaluation of operation for megaoesophagus (cardiospasm). Surgery, 43, 270.

RUSSELL, J.C. (1898) Diagnosis and treatment of spasmodic stricture of the oesophagus. Brit. med. J. 1, 1450.

SCHRIRE, T. (1938) Bilateral bronchiectesis with cardiospasm. Lancet, ii, 1125.

Schultz, E.H., JR (1961) Achalasia in children as a cause of recurrent pulmonary disease. J. Pediat. 59, 522.

Segar, L.H. \& Stoeffler, W. (1930) Cardiospasm in the newborn infant. Amer. J. Dis. Child. 39, 354.

Sifers, E.C. \& CRILES, G., JR (1960) Cardiospasm: a review of 100 cases. Gastroentrology, 16, 466.

Sliesinger, M.H., Steinberg, H. \& Almy, T.P. (1953) The disturbance of oesophageal motility in cardiospasm. Gastroentrology, 25, 333.

Steichen, F.M., Heller, E. \& Ravitch, M.M. (1960) Achalasia of the oesophagus. Surgery, 47, 846.

SweET, R.H. (1956) Surgical treatment of achalasia of the oesophagus. New Engl. J. Med. 254, 87.

Swenson, O., Merrill, K., Pierce, E.C. \& Rheinlander, H.D. (1940) Blood and nerve supply of oesophagus. $J$. Thoracic Surg. 41, 1141.

Swenson, O. \& OECONOMOPOulos, C.T. (1961) Achalasia of the oesophagus in children. J. Thoracic Cardiovasc. Surg. 41, 49.

Templeton, F.E. (1948) Movements of the oesophagus in the presence of cardiospasm and other oesophageal diseases: a roentgenologic study of muscular action. Gastroentrology, 10, 96.

TeXter, E.C., JR, Smith, W.H., Stickley, H.J. \& Barborka, J. (1956) The nature of achalasia. Gastroentrologia, 86, 187.

Thieding, F. (1921) Ueber Cardiospasmus Atonie und 'Idiopathische' Dilatation der Speiserohre. Beitr. Z. klin. Chir. 121, 237.
Thompson, J. (1950) Neuromuscular incoordination at the cardia in newborn. Arch. Dis. Childh. 25, 52.

Trounce, J.R., Deuchar, D.C., Kauntze, R. \& Thomas, G.A. (1957) studies in achalasia of the cardia. Quart. J. Med. 26, 433.

Tuttle, W.M., Crowley, R.T. \& Barett, R.J. (1958) Achalasia of the oesophagus-further thoughts on surgical management. J. Thoracic Surg. 36, 453.

VAN DER BOGART, F. (1933) Cardiospasm in the newborn. Arch. Pediat. 50, 588.

Vinson, P.P. (1924) The diagnosis and treatment of cardiospasm. J. Amer. med. Ass. 82, 859.

Vinson, P.P. (1927) Cardiospasm complicated by pulmonary abscess. A case report. Amer. J. Surg. 2, 359.

VINSON, P.P. (1948) Diagnosis and treatment of cardiospasm. Postgrad. Med. 3, 13.

von RokitanSKy, C. (1842) Abnomataten des Calibers Und der Dicke der Wandungi. Handb. path. Anat. 2, 159.

WANGENSTEEN, O.H. (1951) The physiologic operation for megaoesophagus (dystonia, cardiospasm, achalasia). Ann. Surg. 134, 30.

WANGENSTEEN, O.H. (1957) Technique of achieving an adequate extramucosal myotomy in megaoesophagus (achalasia, cardiospasm, dystonia). Surg. Gynec. Obstet. $105,339$.

WeISS, E. (1944) Cardiospasm: a psychosomatic disorder. Psychosom. Med. 6, 58.

Wendel, W. (1910) Zur Chirurge des Oesophagus. Arch. klin. Chir. 93, 311.

Womack, N.A., Britnell, E.S. \& Ehrenhaft, J.L. (1951) Benign obstruction of the lower oesophagus. J. Amer. med. Ass. 145, 283.

ZaAIGer, J.H. (1923) Cardiospasm in the aged. Ann. Surg. 77,615 . 